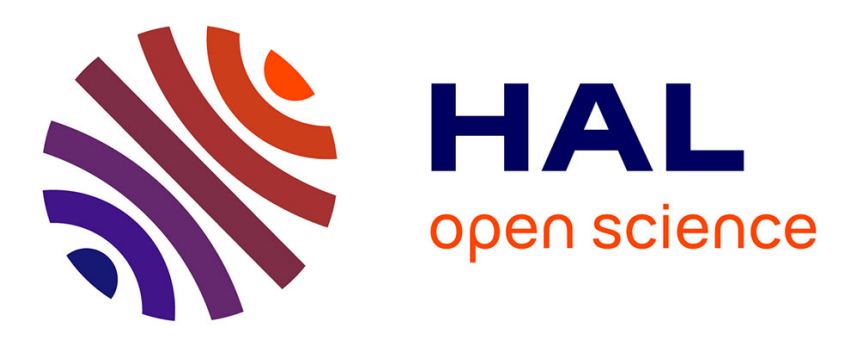

\title{
Effect of relative humidity on carvacrol release and permeation properties of chitosan based films and coating
}

Mia Kurek, Alain Guinault, Andrée Voilley, Kata Galic, Frédéric Debeaufort

\section{- To cite this version:}

Mia Kurek, Alain Guinault, Andrée Voilley, Kata Galic, Frédéric Debeaufort. Effect of relative humidity on carvacrol release and permeation properties of chitosan based films and coating. Food Chemistry, 2014, 144, pp.9-17. 10.1016/j.foodchem.2012.11.132 . hal-00980586

\section{HAL Id: hal-00980586 https://hal.science/hal-00980586}

Submitted on 16 May 2014

HAL is a multi-disciplinary open access archive for the deposit and dissemination of scientific research documents, whether they are published or not. The documents may come from teaching and research institutions in France or abroad, or from public or private research centers.
L'archive ouverte pluridisciplinaire HAL, est destinée au dépôt et à la diffusion de documents scientifiques de niveau recherche, publiés ou non, émanant des établissements d'enseignement et de recherche français ou étrangers, des laboratoires publics ou privés. 


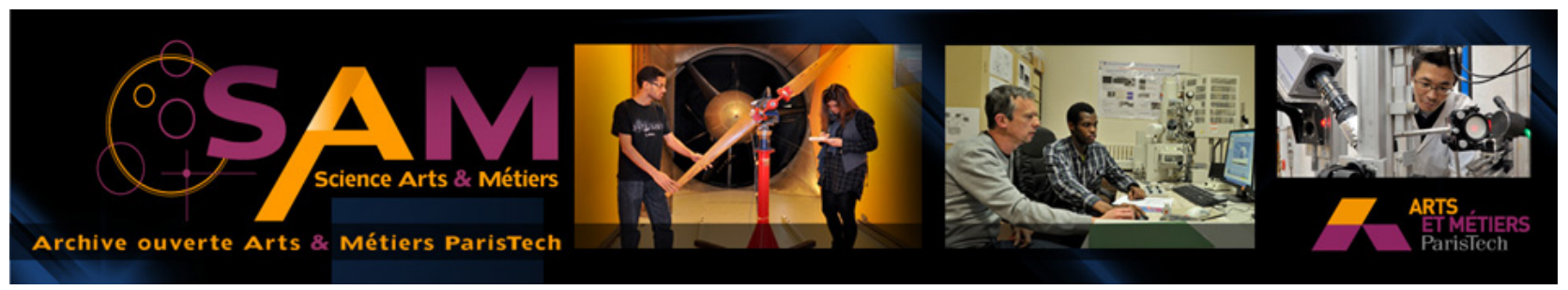

Science Arts \& Métiers (SAM)

is an open access repository that collects the work of Arts et Métiers ParisTech researchers and makes it freely available over the web where possible.

This is an author-deposited version published in: http://sam.ensam.eu

Handle ID: .http://hdl.handle.net/10985/7982

\section{To cite this version :}

Mia KUREK, Alain GUINAULT, Andrée VOILEY, Kata GALIC, Frédéric DEBEAUFORT - Effect of relative humidity on carvacrol release and permeation properties of chitosan based films and coating - Food Chemistry - Vol. 144, p.9-17 - 2014 


\title{
Effect of relative humidity on carvacrol release and permeation properties of chitosan based films and coatings
}

\author{
Mia Kurek ${ }^{\mathrm{a}, \mathrm{b}}$, Alain Guinault ${ }^{\mathrm{c}}$, Andrée Voilley $^{\mathrm{a}}$, Kata Galić ${ }^{\mathrm{b}}$, Frédéric Debeaufort ${ }^{\mathrm{a}, \mathrm{d}, *}$ \\ ${ }^{a}$ PAM-PAPC, 1 esplanade Erasme, Université de Bourgogne - Agrosup Dijon, F-21000 Dijon, France \\ ${ }^{\mathrm{b}}$ Laboratory for Food Packaging, Faculty of Food Technology and Biotechnology, University of Zagreb, HR-10000 Zagreb, Croatia \\ c PIMM - CNAM, 151 boulevard de l'hôpital, 75013 Paris, France \\ ${ }^{\mathrm{d}}$ IUT-Dijon Departement Genie Biologique, 7 Boulevard Dr. Petitjean, B.P. 17867, F-21078 Dijon Cedex, France
}

Keywords:

Biopolymer

Relative humidity

Permeability

Contact angle

Active compound release

Swelling

\begin{abstract}
A B S T R A C T
The influence of water vapour conditions on mass transport and barrier properties of chitosan based films and coatings were studied in relation to surface and structural properties. Water contact angles, material swelling, polymer degradation temperature, barrier properties $\left(\mathrm{PO}_{2}, \mathrm{PCO}_{2}, \mathrm{WVP}\right)$ and aroma diffusion coefficients were determined. The solvent nature and the presence of carvacrol influenced the surface and structural properties and then the barrier performance of activated chitosan films. Increasing RH from $0 \%$ to $100 \%$ led to a significant increase in material swelling. The plasticization effect of water was more pronounced at high humid environment, while at low RH the matrix plasticization was induced by carvacrol. The deposit of a thin chitosan layer on polyethylene decreased $\mathrm{PO}_{2}$ and $\mathrm{PCO}_{2}$ both in dry and humid conditions. The carvacrol release from the chitosan matrix was strongly influenced by RH. A temperature increase from 4 to $37{ }^{\circ} \mathrm{C}$ also had an impact on carvacrol diffusivity but to a lesser extent than RH.
\end{abstract}

\section{Introduction}

Active packaging and more specifically antimicrobial packaging films are innovative concepts in food packaging. They have been developed to meet consumer demand for greater food and microbiological safety. Indeed, these systems provide greater efficiency in food protection because they allow the stability of the antimicrobial agent, and ensure the control of its release to the food over time. For example, a too slow release might cause insufficient microbial inhibition, while a too fast release might be the reason why the inhibition is not sustained (Li, Kennedy, Peng, Yie, \& Xie, 2006). The release rate depends on the polymer type, on the film preparation method, on the interactions between polymeric and antimicrobial materials (Cha, Cooksey, Chinnan, \& Park, 2003) and environmental conditions (Cagri, Ustunol, \& Ryser, 2004). Therefore, developing new antimicrobial delivery technologies and utilising them in product development is crucial for food industries to compete and survive.

Much research in material sciences is focused on the structureproperties relationship to predict and to control the functional film properties. Currently, special attention is given to chitosan, $\mathrm{N}$-acet-

* Corresponding author at: PAM-PAPC, 1 esplanade Erasme, Université de Bourgogne - Agrosup Dijon, F-21000 Dijon, France. Tel.: +33 38039 6547; fax: +33 380396469 .

E-mail address: frederic.debeaufort@u-bourgogne.fr (F. Debeaufort).
yl-D-glucosamine, due to its low toxicity, biodegradability, stability and relatively low cost as it is a by-product and a renewable material from some industries. Chitosan is a water sensible material that naturally interacts with water. Yakimets et al. (2007) determined the water content of biopolymer films as a critical variable that leads to water-induced transformations (for example, amorphous-crystalline transition) that have a strong impact on the molecular mobility and functional properties. The crystalline structure of hydrated chitosan is a twofold helix. This structure can be converted to a dehydrated form, very similar to the hydrated one, but with molecular packing and water content quite different (Ogawa, Yui, \& Okuyama, 2004). Moisture has a plasticizing or swelling effect on polymers, so it increases gas permeability (Ashley, 1985). Water increases the polymer-free volume, allowing the segments of polymeric chains to be mobile (McHugh, Aujard, \& Krochta, 1994). Moreover, in order to satisfy adequate functional properties, the film must be designed according to some surface properties. Contact angle measurements enable investigation of the wetting behaviour of the biopolymer surface and can be a good indicator for the determination of their hydrophilic nature (Peroval, Debeaufort, Despre, \& Voilley, 2002). Then it represents a good way for the development of hydrophilic biodegradable and well-characterised delivery systems and for understanding the mechanisms of polymer surface degradation and active compound release, which could be of importance both for food packaging and for pharmaceutical applications. However, poor water resistance 
and mechanical performance are limiting factors for use of biopolymer materials manufactured only from natural polymers. That is why there is growing demand in development and characterisation of bio-based/synthetic polymer systems.

Today, it is very fashionable to use essential oils and their constituents as they show a great potential to be used as antimicrobial compounds both in direct food contact and via vapour. Carvacrol is a phenolic compound extracted from oregano and thyme oil. Its inhibitory effect on the growth of various microorganisms is well documented and described extensively (Ben Arfa, Combes, Preziosi-Belloy, Gontard, \& Chalier, 2006; Burt, 2004; Nostro \& Papalia, 2012).Carvacrol might be incorporated within biopolymer material that can be used as a self standing film or it can be coated onto the synthetic packaging materials. The efficiency of this system is determined by the controlled diffusion and release and is maintained in concentrations high enough for antimicrobial impact where necessary. The use of volatile antimicrobial agents has many advantages. This system can be used effectively for fresh products such as meat, cheese, fruits, vegetables, or dry products, highly porous food etc. Because spices and extracts provide the majority of volatile antimicrobial agents and are commonly GRAS classified (Generally Recognised As Safe), this system is linked to the food and pharmaceutical research and development area and is easily accepted by consumers and regulatory bodies.

During the storage and the use of packaging material, the properties of chitosan films may be changed after the incorporation of active compound. The loss of active volatile compounds from bio-based matrix at specified temperature and relative humidity $(\mathrm{RH})$ (that will simulate the timeline in the 'real food product' shelf life), requires the knowledge of the polymer water sensitivity, the diffusion coefficient of active compounds, release rates and migration amounts according to moisture levels. Mass transfers through food packaging films exist whatever the type of material used, even if several of them are associated. The transfer mechanism of molecules like water vapour and gases through the film are different according to the film structure that might be changed during processing and storage. Increased storage temperature and humidity can accelerate the migration of the active agents in the film. Thus, the protective action of antimicrobial films will be minimized, due to the high diffusion rates in the polymer and in the food.

The aim of this study was to investigate the influence of $\mathrm{RH}$ on the surface and thermal properties of bio-based polymer self standing films and coatings applied onto polyethylene films. For this purpose we used chitosan and carvacrol as models of biopolymer matrices and active compounds with an antimicrobial potential. The effect of incorporated carvacrol on the structure changes was studied. Water vapour, oxygen and carbon dioxide permeability has also been studied in order to monitor the film behaviour according to the temperature and $\mathrm{RH}$. Furthermore, to better understand the influence of both temperature and $\mathrm{RH}$ on the carvacrol release, kinetics were studied at 4, 20 and $37{ }^{\circ} \mathrm{C}$ and $0 \%, 75 \%$ and $>96 \%$ RH during more than 2 months. Chosen temperatures represent the storage conditions of most fresh food products, of ambient conditions or conditions of use, and those for optimal microbial growth.

\section{Materials and methods}

\subsection{Materials and reagents}

Commercial grade chitosan (CS) (France Chitine, Marseille, France, powder 652, having a molecular mass of $165 \mathrm{kDa}$, low viscosity, food grade, degree of deacetylation of $>85 \%$ ) was used as the film-forming matrix. A commercial, low density polyethylene film (LDPE) (Wipak, Lille, LD-PE45 UFP; thickness of $45 \mu \mathrm{m}$ ) was used as a polyolefin material. Carvacrol (CVC) (purity $>97 \%$, Fluka) was used as the aroma compound in order to improve the functional film properties. Acetic acid (glacial 100\%, Merck, Darmstadt, Germany) and pure ethanol (absolute, Sigma-Aldrich) were used as solvents in the preparation of the film forming solutions (FFS). Silica gel, magnesium chloride $\left(\mathrm{MgCl}_{2}\right.$, Sigma), sodium chloride $(\mathrm{NaCl}$, Sigma) were used to prepare saturated salt solutions to fix the $\mathrm{RH}$ at $<2 \%, 33 \%$ and $75 \%$ and for water vapour permeability measurements, aroma release measurements and for sample conditioning prior to thermal analysis. Deionised water was used for surface analysis, aroma release determination and to fix $\mathrm{RH}$ at $>96 \%$ for permeability measurements. No further purification of chemicals has been done and freshly prepared solutions were always used.

\subsection{Film preparation}

\subsubsection{Self standing chitosan films}

A chitosan solution was prepared by dissolving the chitosan powder in a $1 \%(\mathrm{v} / \mathrm{v})$ aqueous acetic acid, to obtain $2 \%(\mathrm{w} / \mathrm{v})$ film forming solutions (FFS). To achieve a complete dispersion of the chitosan, the solution was stirred for $2 \mathrm{~h}$ at room temperature. To prepare the aqueous hydroalcoholic acid media, ethanol was mixed in a ratio ethanol:aqueous acetic acid of 30:70. Carvacrol $(0.5 \%, \mathrm{w} / \mathrm{v})$ was homogenised either in aqueous acid CS solution or hydroalcoholic acid CS solution at $24000 \mathrm{rpm}$ for $10 \mathrm{~min}$ with an Ultra Turrax (T25 IKA) to obtain film forming solutions with an incorporated aroma compound. In order to obtain films, solvents were removed by drying in a ventilated climatic chamber (KBF 240 Binder, ODIL, France) at $20^{\circ} \mathrm{C}$ and $30 \%$ RH. After drying, the films were peeled off and stored in the same ventilated climatic chamber at $25{ }^{\circ} \mathrm{C}$ and $30 \% \mathrm{RH}$ before measurements. The films prepared in the acetic acid solution were coded as CSA, those in hydroalcoholic acid solution as CSE and those containing carvacrol as CVC.

\subsubsection{Chitosan coated polyethylene films}

The hydroalcoholic acid chitosan solution with/or without carvacrol was prepared as described in Section 2.2.1. The coating was carried out according to Sollogoub et al. (2009), at room temperature, using a Nordson slot die (ChameleonTM), appropriate to fluids of viscosity ranging between 0.5 and $2 \mathrm{~Pa} / \mathrm{s}$. The die is fed continuously by a gear pump, the flow rate of which is adjustable from 5 to $500 \mathrm{~mL} / \mathrm{min}$. A roll winding device creates the movement of the support material at a speed ranging between 0.2 and $4 \mathrm{~m} /$ min. The deposit width is set to $100 \mathrm{~mm}$ and the die opening to $150 \mathrm{~m}$. Films were dried in a flow of a dry air at $50^{\circ} \mathrm{C}$ and $\mathrm{RH}$ $<10 \%$. After drying, the films were stored in a ventilated climatic chamber (KBF 240 Binder, ODIL, France) before measurements at $25^{\circ} \mathrm{C}$ and $30 \% \mathrm{RH}$.

\subsection{Film characterisation}

\subsubsection{Film thickness}

The film thickness was measured with an electronic gauge (PosiTector 6000, DeFelsko Corporation, USA). The average value of five thickness measurements per type of film was used in all calculations.

\subsubsection{Contact angle and wettability}

The contact angle, surface hydrophobicity and wettability of films were measured by the sessile drop method, in which a droplet of the tested liquid was placed on a horizontal film surface using a DGD-DX goniometer (GBX, Romans-sur-Isere, France), equipped with the DIGIDROP image analysis software (GBX, Romans-sur-Isere, France) according to Karbowiak, Debeaufort, and Voilley (2006). Water droplets (1.5 $\mu \mathrm{L}$ approx.) were deposited 
on the film surface ('air side or support side') with a precision syringe. The experimentally acquired data were: contact angle $(\theta)$, droplet surface area exposed to air, droplet base area in contact with the film and droplet volume $(\mathrm{V})$ as a function of time $(\mathrm{t})$. The effect of evaporation was analysed on an aluminium foil which is considered to be totally impermeable to water and aqueous solutions. The wetting kinetics lasted for $200 \mathrm{~s}$. All the films were stored in a climatic chamber (KBF 240 Binder, ODIL, France) at $30 \% \mathrm{RH}$ and $25^{\circ} \mathrm{C}$ prior to measurements. At least six measurements per film were carried out.

\subsubsection{Aroma compound release}

In order to follow the carvacrol release, an extraction technique and a gas chromatography analysis were performed. Samples were conditioned at $<2 \%, 75 \%$ and $>96 \% \mathrm{RH}$ and 4,20 and $37{ }^{\circ} \mathrm{C}$ for more than 60 days. At each sampling time, the dosage of the carvacrol residues was tested according to Kurek, Descours, Galić, Voilley, and Debeaufort (2012a). For each sample three repetitions were performed. To determine diffusion coefficient of carvacrol, Fick's second law was used which describes the change in the concentration of diffusing molecules in the films with respect to time and position. To be able to use Fick's second law, it was assumed that there is no chemical reaction between carvacrol and film matrix. Thus the mass transfer in the film takes place only by diffusion coefficient of carvacrol in the film, D, considered as constant. A solution of Fick's second law is given by Crank (1975). Carvacrol apparent diffusivity was estimated by fitting Eq. (1) to the experimental kinetic data using a pre-estimation of D using Excel.

$\left.\frac{M_{t}}{M_{0}}=\sum_{n=0}^{\infty} \frac{8}{(2 n+1)^{2} \pi^{2}} \exp -\frac{(2 n+1)^{2} \pi^{2}}{4 L^{2}} D t\right)$

where $t$ is the time (s) and $M_{t}$ the amount of carvacrol released from the film at time $t(\mathrm{~g} / \mathrm{g})$. The equation was fit with $n=6$.

\subsubsection{Water vapour permeability measurement (WVP)}

The WVP of films was determined gravimetrically using a modified ASTM E96-80 (1980) standard method, adapted to edible materials by Debeaufort, Martin-Polo, and Voilley (1993), using the $\mathrm{RH}$ differentials of $33-0,75-30$ and $100-30 \%$ and the temperature of $25 \pm 1{ }^{\circ} \mathrm{C}$. Prior to the WVP measurements, all the film samples were equilibrated at $25 \pm 1{ }^{\circ} \mathrm{C}$ and $30 \% \mathrm{RH}$ for $72 \mathrm{~h}$. The film samples were then placed between two Teflon rings on the top of the glass cell containing a silica gel $(<2 \%)$, salt solutions of $\mathrm{MgCl}_{2}$ ( $\mathrm{RH} \sim 33 \%$ ), $\mathrm{NaCl}(\mathrm{RH} \sim 75 \%$ ) or distilled water ( $\mathrm{RH} \sim 100 \%$ ). These permeation cells were introduced into a ventilated chamber (KBF 240 Binder, ODIL, France) maintained at $30 \% \mathrm{RH}$ and $25 \pm 1{ }^{\circ} \mathrm{C}$. WVP $(\mathrm{g} / \mathrm{m} \mathrm{s} \mathrm{Pa})$ was calculated using the following equation, from the change in the cell weight versus time at the steady state:

$W V P=\frac{\Delta m}{\triangle t * \Delta p * A} * e$

where $\Delta m / \Delta t$ is the weight of moisture loss per unit of time $(\mathrm{g} / \mathrm{s}), A$ is the film area exposed to the moisture transfer $\left(9.08 \times 10^{-4} \mathrm{~m}^{2}\right)$, e is the film thickness $(m)$, and $\Delta p$ is the water vapour pressure differential between the two sides of the film $(\mathrm{Pa})$. Three replicates for each film type and RH gradient were made.

\subsubsection{Gas permeability measurements}

The gas permeability determination was performed using a manometric method, on a permeability testing appliance, Brugger, Type GDP-C (Brugger Feinmechanik GmbH, Germany). The increase in pressure during the test period was assessed and displayed by an external computer. Data were recorded and permeance was calculated by a GDP-C Software (with temperature compensation connection). The sample temperature $\left(25^{\circ} \mathrm{C}\right)$ was adjusted using an external Thermostat (HAAKE F3 with Waterbath $\mathrm{K})$. The desired $\mathrm{RH}(\sim 96 \%)$ was regulated in external saturation system. Then, humidified gas circulated in the permeation cell.

\subsubsection{Differential scanning calorimetry (DSC)}

A differential scanning calorimetry was performed using a DSC Q1000-0506 (TA Instruments). An empty capsule was used as an inert reference and the calibration was performed using the indium standard. The accuracy of the measurements was estimated at $\pm 0.1^{\circ} \mathrm{C}$. The heating and the cooling rates under nitrogen atmosphere were fixed at $10^{\circ} \mathrm{C} / \mathrm{min}$. Since chitosan is a hydrophilic polymer which tends to retain moisture, the experiment consisted of the 2 runs in order to eliminate the moisture effect. The following temperature program that ranged between 80 and $350{ }^{\circ} \mathrm{C}$ was used for all the samples: (a) equilibrating at $25^{\circ} \mathrm{C}$, cooling from 25 to $-80^{\circ} \mathrm{C}$ at a rate of $10^{\circ} \mathrm{C} / \mathrm{min}$, isothermal for $10 \mathrm{~min}$ and heating to $220^{\circ} \mathrm{C}$, isothermal for $5 \mathrm{~min}$, (b) cooling down to $-80^{\circ} \mathrm{C}$, isothermal for $10 \mathrm{~min}$, (c) reheating to $350^{\circ} \mathrm{C}$, isothermal for $5 \mathrm{~min}$, (d) and finally cooling down to $25^{\circ} \mathrm{C}$. Prior to the experiment samples were conditioned at $25{ }^{\circ} \mathrm{C}$ and $<2 \%, 75 \%$ and $>96 \% \mathrm{RH}$ for at least 7 days. Reproducibility was tested by carrying out the two measurements for each sample. The mass of all the samples was around $10 \mathrm{mg}$.

\subsubsection{Statistical analysis}

The statistical analysis of the data was performed through variance analysis (ANOVA) using Xlstat-Pro (win) 7.5.3. (Addinsoft, New York). The data were ranked and statistical differences were evaluated on the ranks with a one-way analysis of variance (ANOVA) and Tukey's multiple comparison tests. In all cases, a value of $p<0.05$ was considered to be significant.

\section{Results}

\subsection{Surface hydrophobicity and wettability}

First of all, material wettability was tested in order to better understand how relative humidity $(\mathrm{RH})$ influences the surface properties of chitosan/carvacrol based films and coatings. The contact angle is dependent on the relative magnitude of cohesive and adhesive molecular forces that exist respectively within the liquid and between the liquid and the solid. To estimate the resistance of films to liquid moisture, contact angle (that indicates surface hydrophobicity) at the time of deposit ( $0 \mathrm{~s}$ ) and at metastable equilibrium ( $30 \mathrm{~s}$ ), water absorption rate (wettability), swelling and delay of swelling of chitosan based films and chitosan coated polyethylene (PE) films were determined. Results are given in Table 1 . Practically, a large $\left(\theta>65^{\circ}\right)$ and small $\left(\theta<65^{\circ}\right)$ contact angles represent the quantitative definition of a hydrophobic and hydrophilic surfaces, respectively (Vogler, 1998). Moreover, in a parallel study surface free energy and critical surface tension were determined (Kurek et al., 2012b). These parameters allow the estimation of materials hydrophobicity. From Table 1 and Fig. 1 three types of behaviour can be observed. Changes in behaviour were depended on the polymer nature, the nature of the solvents used in chitosan film preparation and the carvacrol addition.

First of all, during the experiment, the contact angle of water droplet deposited on the PE film linearly decreased. This phenomenon was mainly due to evaporation and spreading. Indeed, the water cannot be absorbed on the PE, because it is a dense material with a maximum capacity of water absorption less than $0.2 \%$ of its mass. It can neither be spread because in this case the volume of drop would be kept constant. The adsorption rate is affected when the excess water evaporates during the measurement. Thus, the "adsorption" rate on aluminium foil was determined to estimate 
Table 1

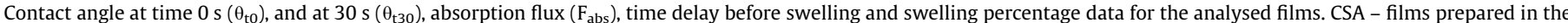

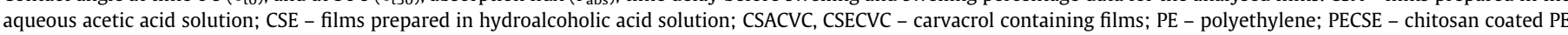
film; PECSECVC - chitosan film containing carvacrol coated PE film.

\begin{tabular}{|c|c|c|c|c|c|c|}
\hline Film & Side & $\theta_{\mathrm{t} 0}\left({ }^{\circ}\right)$ & $\theta_{\mathrm{t} 30}\left(^{\circ}\right)$ & $\mathrm{F}_{\mathrm{abs}}\left(10^{-3} \mu \mathrm{L} / \mathrm{mm}^{2} \mathrm{~s}\right)$ & Delay before swelling (s) & Swelling (\%) \\
\hline \multirow[t]{2}{*}{ CSA } & Air & $93.64 \pm 0.23^{b, c}$ & $89.88 \pm 0.18^{\mathrm{b}, \mathrm{c}}$ & Direct swelling & 1 & $53.51 \pm 5.46^{\mathrm{a}}$ \\
\hline & Support & $88.8 \pm 0.24^{\mathrm{c}}$ & $94.32 \pm 0.76^{\mathrm{a}, \mathrm{b}}$ & $1.15 \pm 0.06^{\mathrm{b}, \mathrm{c}}$ & $2.9 \pm 0.42^{\mathrm{d}, \mathrm{e}}$ & $41.26 \pm 0.99^{\mathrm{a}, \mathrm{b}, \mathrm{c}}$ \\
\hline \multirow[t]{2}{*}{ CSACVC } & Air & $42.17 \pm 0.75^{\mathrm{e}}$ & $34.05 \pm 0.95^{\mathrm{e}}$ & $1.50 \pm 0.37^{\mathrm{a}, \mathrm{b}}$ & $72.4 \pm 11.03^{\mathrm{a}}$ & $31.89 \pm 0.72^{\mathrm{b}, \mathrm{c}}$ \\
\hline & Support & $98.71 \pm 1.78^{\mathrm{a}, \mathrm{b}}$ & $91.33 \pm 1.11^{\mathrm{b}, \mathrm{c}}$ & $1.65 \pm 0.12^{\mathrm{a}}$ & 1 & 1 \\
\hline \multirow[t]{2}{*}{ CSE } & Air & $87.26 \pm 0.51^{\mathrm{c}}$ & $89.90 \pm 1.57^{\mathrm{b}, \mathrm{c}}$ & $0.32 \pm 0.02^{\mathrm{d}}$ & $10.8 \pm 1.13^{\mathrm{c}, \mathrm{d}}$ & $22.89 \pm 1.79^{c}$ \\
\hline & Support & $88.19 \pm 2.44^{c}$ & $86.50 \pm 1.25^{\mathrm{a}}$ & $0.95 \pm 0.04^{c}$ & $15.8 \pm 3.39^{c}$ & $51.82 \pm 5.94^{\mathrm{a}}$ \\
\hline \multirow[t]{2}{*}{ CSECVC } & Air & $47.28 \pm 5.86^{d}$ & $38.27 \pm 3.12^{\mathrm{a}}$ & $1.48 \pm 0.19^{\mathrm{a}, \mathrm{b}}$ & $28.67 \pm 6.31^{b}$ & $41.51 \pm 15.92^{\mathrm{a}, \mathrm{b}}$ \\
\hline & Support & $100.64 \pm 9.52^{\mathrm{a}}$ & $92.27 \pm 10.39^{\mathrm{a}, \mathrm{b}, \mathrm{c}}$ & $1.40 \pm 0.26^{\mathrm{a}, \mathrm{b}, \mathrm{c}}$ & 1 & 1 \\
\hline PE & & $90.18 \pm 2.07^{c}$ & $85.48 \pm 4.28^{\mathrm{d}}$ & Evaporation & i & i \\
\hline \multirow[t]{2}{*}{ PECSE } & $\mathrm{PE}$ & $88.70 \pm 3.77^{c}$ & $87.99 \pm 3.78^{\mathrm{c,d}}$ & Evaporation & i & i \\
\hline & CSE & $93.58 \pm 0.52^{\mathrm{c}}$ & $90.70 \pm 0.59^{\mathrm{b}, \mathrm{c}}$ & $0.40 \pm 0.03^{\mathrm{d}}$ & 1 & i \\
\hline \multirow[t]{2}{*}{ PECSECVC } & $\mathrm{PE}$ & $93.26 \pm 1.04^{c}$ & $91.95 \pm 1.46^{\mathrm{a}, \mathrm{b}, \mathrm{c}}$ & Evaporation & 1 & 1 \\
\hline & CSECVC & $89.63 \pm 0.11^{\mathrm{c}}$ & $88.45 \pm 0.28^{\mathrm{b}, \mathrm{c}, \mathrm{d}}$ & $1.08 \pm 0.25^{\mathrm{b}, \mathrm{c}}$ & $2.93 \pm 0.11^{\mathrm{d}, \mathrm{e}}$ & $39.25 \pm 1.05^{\mathrm{a}, \mathrm{b}, \mathrm{c}}$ \\
\hline
\end{tabular}

Mean of at least five measurements \pm standard deviation. Values followed by the same letter $\left({ }^{\mathrm{a}-\mathrm{e}}\right)$ are not significantly different at the p-level of $5 \%$.
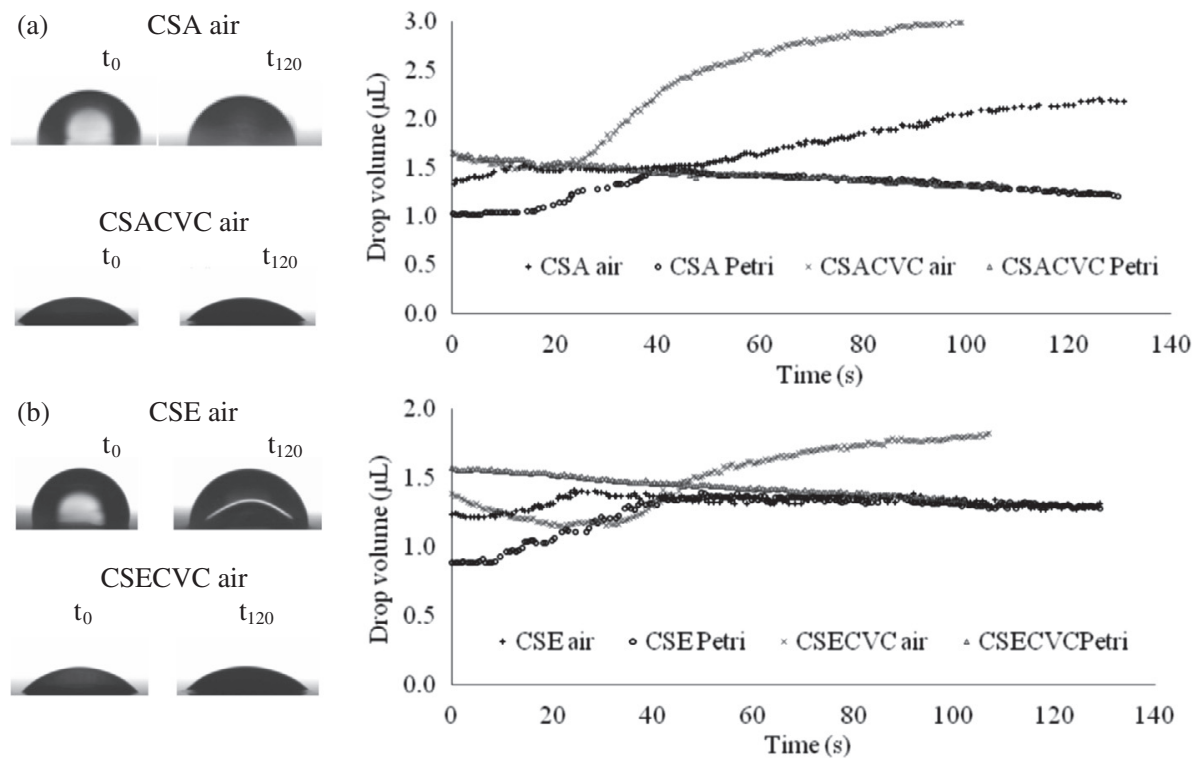

(c) PECSE side PE

$\mathrm{t}_{0} \quad \mathrm{t}_{120}$

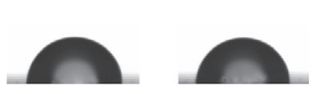

PECSE side CSE

$\mathrm{t}_{0} \quad \mathrm{t}_{120}$
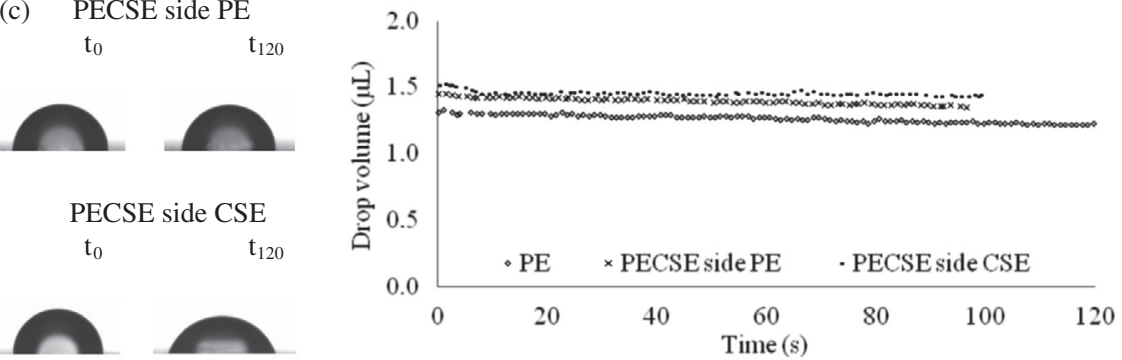

(d) PECSECVC side PE
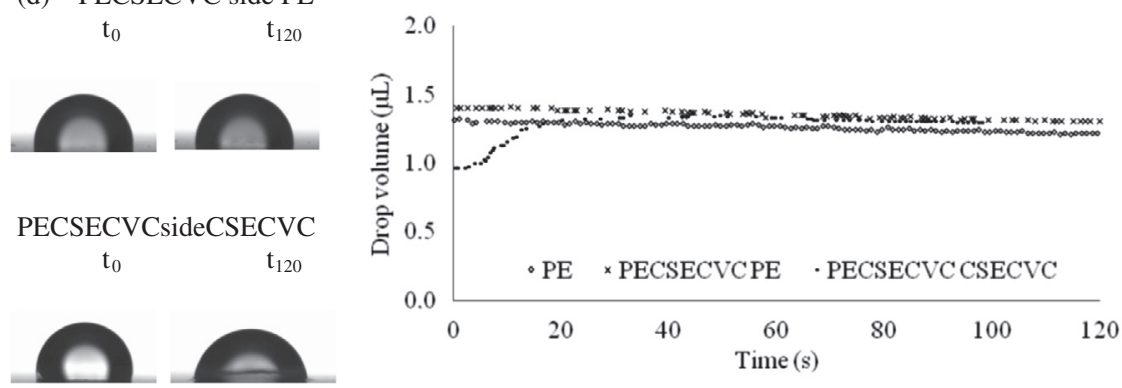

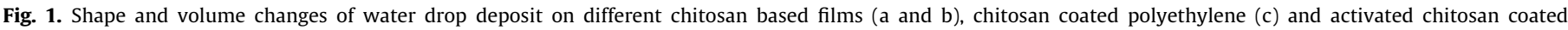
polyethylene (d). 
the evaporation rate of the measurement, considering that aluminium does not significantly absorb water during the measurement. The data obtained on aluminium were similar to those on PE, confirming that evaporation is predominant. On the coated PE the water droplet profile began to change immediately upon deposition onto the chitosan-coated surface (Fig. 1). Close values of surface free energies ( 35.76 and $37.32 \mathrm{mN} / \mathrm{m}$ for PE and coated PE, respectively), explain why no significant changes were observed in the contact angle values of PE and coated PE. Still, the presence of the thin chitosan layer $(6 \mu \mathrm{m})$ caused the swelling of the coated side.

Contrarily, films based on chitosan have non-linear behaviour where changes such as solvatation, hydration and/or swelling occurred (Fig. 1 and Table 1). This behaviour differed depending on the solvent and the presence of carvacrol (CVC). Moreover, a different response was observed from the "air" to the "support" side. Thus, films prepared in the aqueous acidic solution (CSA) tend to be swollen (with a surface deformation) on the air side, since after submission an immediate increase in the drop volume was observed. Contrarily, films prepared in the hydroalcoholic acid solution (CSE) also swelled. The swelling occurred after the first absorption that was characterised by a decrease in both volume and contact angle of water droplet. The presence of water at the surface of chitosan results in low frictional surface forces, which is a desirable property in developing biocompatible materials. Moreover during contact angle measurement the swelling phenomenon was induced probably due to the plasticization by water and partial solubilisation of chitosan macromolecular chains. This behaviour seems to be contradictory to that observed for the water vapour permeability, which showed a lower resistance of CSE films to water transfer (results will be discussed later). Farris et al. (2011) stated that reduction in the solid/liquid contact area is accompanied by a steep decrease in volume. Taking this into account, the sensitivity of films to the liquid moisture transfer was evaluated by the determination of the water droplet adsorption rate. The water adsorption rate of the air side of CSA film was not determined because the film started to swell directly as the water droplet was deposited. This phenomenon was followed by a decreased hydrophobicity which favoured the wetting of the surface and thus the decrease of the contact angle. The absorption period before swelling was longer for air sides of CSACVC and CSECVC films. Moreover, for CSECVC films $F_{a b s}$ was doubled (Table 1). The support sides of carvacrol containing films were the most hydrophobic surfaces (highest contact angle). This might be explained by the different orientation of carvacrol droplets in the support side compared to the air side because of the evaporation phenomenon of carvacrol during film drying. Moreover, this was supported by the lower $\mathrm{F}_{\mathrm{abs}}$ $\left(0.32-1.15 \mu \mathrm{L} / \mathrm{mm}^{2} \mathrm{~s}^{1}\right)$ for air sides of CSA and CSE films than for CSACVC and CSECVC $\left(1.40-1.65 \mu \mathrm{L} / \mathrm{mm}^{2} \mathrm{~s}^{1}\right)$. To deepen analysis, the Owens and Wendt method was used to determine the film interfacial tension. The addition of carvacrol led to a sharp increase of the interfacial tension which should result in a decrease in its wettability and thus its affinity for water. But this was not observed, then the films containing carvacrol absorbed water faster and swelled. That's why this behaviour could be explained by the film structure. Kurek et al. (2012b) pointed out that carvacrol droplets caused irregularities in the polymer matrix. In this case, the surface roughness was increased. Thus, the side effect could be attributed to a reorientation of the molecules during film drying as previously reported (Karbowiak et al., 2006; Ogawa et al., 2004). Additionally, nonpolar impurities in samples might increase surface heterogeneity (Cunha et al., 2008). Consequently, it favoured water penetration because of the capillary forces. Still, the PE coated samples did not exhibit these changes to a large extent, probably due to different drying procedures and lower coating thicknesses.

CSECVC film had higher contact angle values than CSACVC measured at time 0 or $30 \mathrm{~s}$. Hydroalcoholic solvent favoured the solubility of carvacrol and thus a more homogeneous droplet/matrix layer was formed. Here, the side effect was even more pronounced. This behaviour in the presence of carvacrol perfectly supports the results obtained for the water vapour permeability, in particular for the highest RH differential ( $\Delta \mathrm{RH} 100-30 \%)$. The swelling of material is desirable from an application point of view that might be the main guideline in the controlled release of active compounds. Moreover, it turns out that the surface phenomena play an important role in the mechanism of permeation.

\subsection{Thermal properties of chitosan based films influenced by relative humidity}

A thermal analysis was performed in order to confirm the hypothesis about plasticization influenced by water and/or carvacrol. Before measurements, all the samples were conditioned to three $\mathrm{RH}(\sim 0,75$ and $100 \%) . \mathrm{T}_{\mathrm{g}}$ is a value associated with the system mobility and is defined as a physical change from the glassy to the rubbery state in amorphous materials promoted by heat. The determination of $T_{g}$ in chitosan based films was a difficult task because changes in the inclination of the baseline in the DSC thermograms were very weak. That is why we are generally speaking about the dehydration temperature $\left(\mathrm{T}_{\mathrm{d}}\right)$ related to the evaporation process (characteristic phenomenon of hydrophilic polymers), the dissociation temperature related to the dissociation process of the interchain hydrogen bonding of the chitosan $\left(\mathrm{T}_{\mathrm{DS}}\right)$ and the degradation temperature related to the decomposition of the polysaccharide backbone $\left(T_{D}\right)$ (Kurek et al., 2012c). Small endothermic dehydration peaks around 60 and $96^{\circ} \mathrm{C}$ in dry ( $\mathrm{RH} 0 \%$ ) samples indicated that even after conditioning there was still a small quantity of water in the system, probably due to solvent traces after drying. The observed $\mathrm{T}_{\mathrm{DS}}$ values for chitosan films with and without carvacrol changed with the RH. It was attributed to the different intensity of the plasticisation effect of water and carvacrol. When the RH was close to zero, the plasticisation effect of carvacrol was more pronounced. It was attributed to the fact that in the system, there was not enough free water and then, carvacrol had the plasticizing role increasing the mobility of chitosan polymer chains. Thus, in dry systems, $\mathrm{T}_{\mathrm{DS}}$ values were consequently lower for CSECVC $\left(131^{\circ} \mathrm{C}\right)$ than for CSE samples $\left(170{ }^{\circ} \mathrm{C}\right)$. Additional, less energy was needed to establish the film network. Furthermore, $\Delta \mathrm{H}_{\mathrm{d}}, \Delta \mathrm{H}_{\mathrm{DS}}, \Delta \mathrm{H}_{\mathrm{D}}$ of CSECVC (around $0.7,40$ and $90 \mathrm{~J} / \mathrm{g}$ respectively) were lower compared to CSE films (around 2, 70 and $112 \mathrm{~J} / \mathrm{g}$, respectively). When $\mathrm{RH}$ increased, the plasticization effect of water became more pronounced than that of carvacrol. Thus for $75-100 \% \mathrm{RH}$ range the dissociation temperature were lower for samples without carvacrol $\left(133^{\circ} \mathrm{C}\right.$ for CSE and $159{ }^{\circ} \mathrm{C}$ for CSECVC films). When increasing RH, the number of water molecules in the system increases. So the possibility for the chitosan chains to interact with water molecules increases too. The hydrophilic character of chitosan and thus water binding capacity tends to draw additional water into the matrix limiting the interactions of carvacrol with the polymer chains and determine the final distribution of water in the system. The quantity of absorbed water increases and more energy was required (higher enthalpies at higher $\mathrm{RH})$. The remarking effect was also in significant increase in carvacrol release at humidities above $75 \%$ that will be later discussed.

For the chitosan coated samples, only $T_{d}$ and $T_{D}$ temperatures were detected for chitosan part and $\mathrm{T}_{\mathrm{m}}$ for PE. No significant changes were observed due to the low amount of the chitosan when applied as a thin coating layer $(3-6 \mu \mathrm{m})$.

\subsection{Water vapour permeability}

Water vapour permeability (WVP) is the most important and extensive properties of biopolymer films because of its direct 
influence on the deteriorative reactions in packed food. The permeability of films is not a constant (or intrinsic characteristic of the material) because it increases with $\mathrm{RH}$ gradient, contrary to the predicted sorption-diffusion model that describes permeability. This non-ideal behaviour is generally attributed to a structural modification of the film such as swelling due to the sorption of water vapour. This swelling was also observed by others for biopolymers based materials (Karbowiak et al., 2006; Kokoszka, Debeaufort, Hambleton, Lenart, \& Voilley, 2010).

Polyethylene films are known to be very hydrophobic, low moisture sensitive and relatively not permeable to water vapour. Moreover, its WVP does not change with RH differential. In the previous study it was reported (Kurek, Šcetar, Voilley, Galic, \& Debeaufort, 2012d) that the presence of the hydrophilic chitosan layer presented a reservoir of water on the PE surface. It is likely that high water sorption by chitosan resulted in a much higher concentration of water on the surface, even in a liquid state, which favoured the sorption of water by $\mathrm{PE}$, and therefore increased its permeability. At higher RH differentials, the addition of carvacrol in the coating layer decreased WVP, probably because of the hydrophobicity of the aroma compound while at lower RH the effect was opposite.

From Fig. 2 it is evident that all chitosan based films are not good water barrier materials compared to polyethylene. It is probably because of the inherent hygroscopic character of chitosan. Its WVP was nearly 2-3 orders of magnitude greater than that of PE film. Increased moisture pressure gradient significantly affected WVP.

At lower RH differentials (33-0\%), films without aroma compound (CSA and CSE) had lower permeability, from $10 \%$ to $15 \%$, than that containing carvacrol (CSACVC and CSECVC) as shown in Fig 2. This, once again, suggests a plasticizing effect of carvacrol, only noticeable for the lowest $\mathrm{RH}$ and less marked plasticizing effect of water. Despite the increase in the hydrophobic character of the film when carvacrol was added, its incorporation might have negatively influenced the attractive forces between chitosan molecules and it might have increased segmental movements between them (Bonilla, Atarés, Vargas, \& Chiralt, 2012). This hypothesis was reinforced with the DSC results that displayed a modification in $T_{D S}$ and $\mathrm{T}_{\mathrm{D}}$.

The addition of hydrophobic substances could decrease the hydrophilic portion of the film decreasing its affinity for water at high RH (Hernández-Muñoz, López-Rubio, Del-Valle, Almenar, \& Gavara, 2004). But in our study, in self supported chitosan films, the WVP tends to reach a plateau at high moisture environments (Fig. 2). This is due to water impact on the molecular mobility that masked the hydrophobic effect of carvacrol. Then at 75-30\% and at
100-30\% RH differentials WVP were not significantly different. Indeed, adsorbed moisture has a plasticizing effect on the biopolymer network and leads to changes from glassy to rubbery material state (Phan, Debeaufort, Luu, \& Voilley, 2005). At higher RH film swelled and the swollen network of chitosan, together with the decreased density and the local viscosity, facilitated the diffusion of water molecules that was more rapid than through the glassy material.

\subsection{Oxygen and carbon dioxide permeability}

When a chitosan film is applied with a food product, the gas concentration in the packaging may change during the storage. The chemical composition of the food surface is dynamic and biochemical changes in food, microbial respiration, gas solubility and permeability through packaging film will influence product quality. The efficiency of chitosan films and coatings strongly depends on its water vapour and gas barrier properties. These parameters are also depended on the chemical composition and the structure of the film forming polymers, the product characteristics and the storage conditions. To approach the 'real' product conditions, influence of $\mathrm{RH}$ on the oxygen $\left(\mathrm{PO}_{2}\right)$ and carbon dioxide $\left(\mathrm{PCO}_{2}\right)$ barrier properties were examined (Fig. 3). Generally, biopolymers are aimed to be a good barrier to gases at low RH. Thinking of chitosan as a new kind of oxygen-barrier coating material, it is possible to obtain a high oxygen barrier property on common plastic films and also to improve the biodegradability of the produced material.

The $\mathrm{PO}_{2}$ and $\mathrm{PCO}_{2}$ of chitosan coated PE and self standing chitosan films are given in Fig. $3 a$ and b. In dry conditions $\mathrm{PCO}_{2}$ $\left(1 \times 10^{-17} \mathrm{~g} / \mathrm{m} \mathrm{s} \mathrm{Pa}\right)$ was lower than $\mathrm{PO}_{2}\left(6 \times 10^{-17} \mathrm{~g} / \mathrm{m} \mathrm{s} \mathrm{Pa}\right)$ for chitosan coated PE films. The gas permeability of PE films alone was not significantly affected by RH. At the temperatures of study, PE was probably in the rubbery state and as it is apolar material, it should not interact with water molecules. On the contrary, for chitosan coated samples both $\mathrm{PO}_{2}$ and $\mathrm{PCO}_{2}$ were significantly higher at $>96 \% \mathrm{RH}$, precisely 10 times for $\mathrm{PO}_{2}$ and 1000 times for $\mathrm{PCO}_{2}$. The effect of $\mathrm{RH}$ was less pronounced for carvacrol containing coated PE. Already in dry conditions these films were less performing than PECSE. $\mathrm{PO}_{2}$ and $\mathrm{PCO}_{2}$ of PECSECVC at $>96 \%$ increased for 4 and 19 times respectively, but still remained 1.6 and 1.5 times lower than PE film itself. Hagenmeier and Shaw (1991) also reported an exponential increase in $\mathrm{PO}_{2}$ of shellac coatings with increasing $\mathrm{RH}$.

$\mathrm{PO}_{2}$ and $\mathrm{PCO}_{2}$ changes with $\mathrm{RH}$ and composition of self standing chitosan films are given in Fig. 3b. In dry conditions, the permeability of both gases increased with the incorporation of carvacrol. This was mostly due to microstructural changes in the chitosan

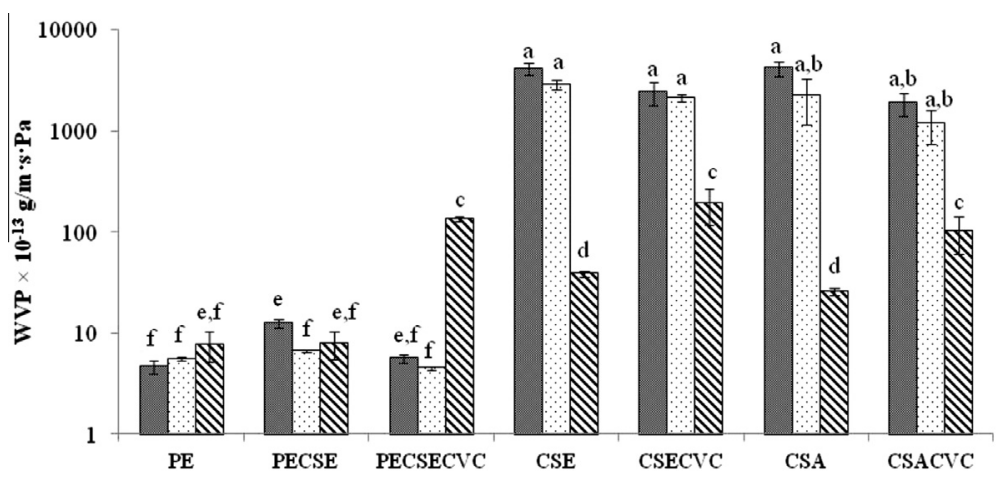

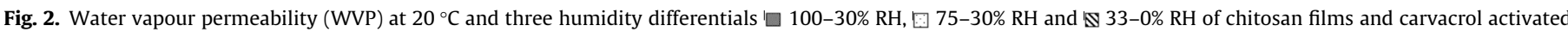

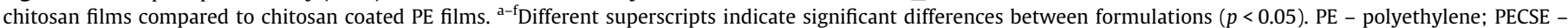

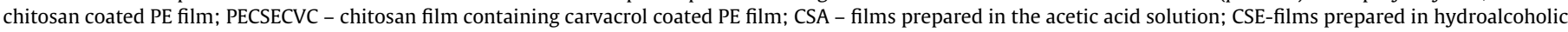
acid solution; CSACVC, CSECVC - carvacrol containing films. 

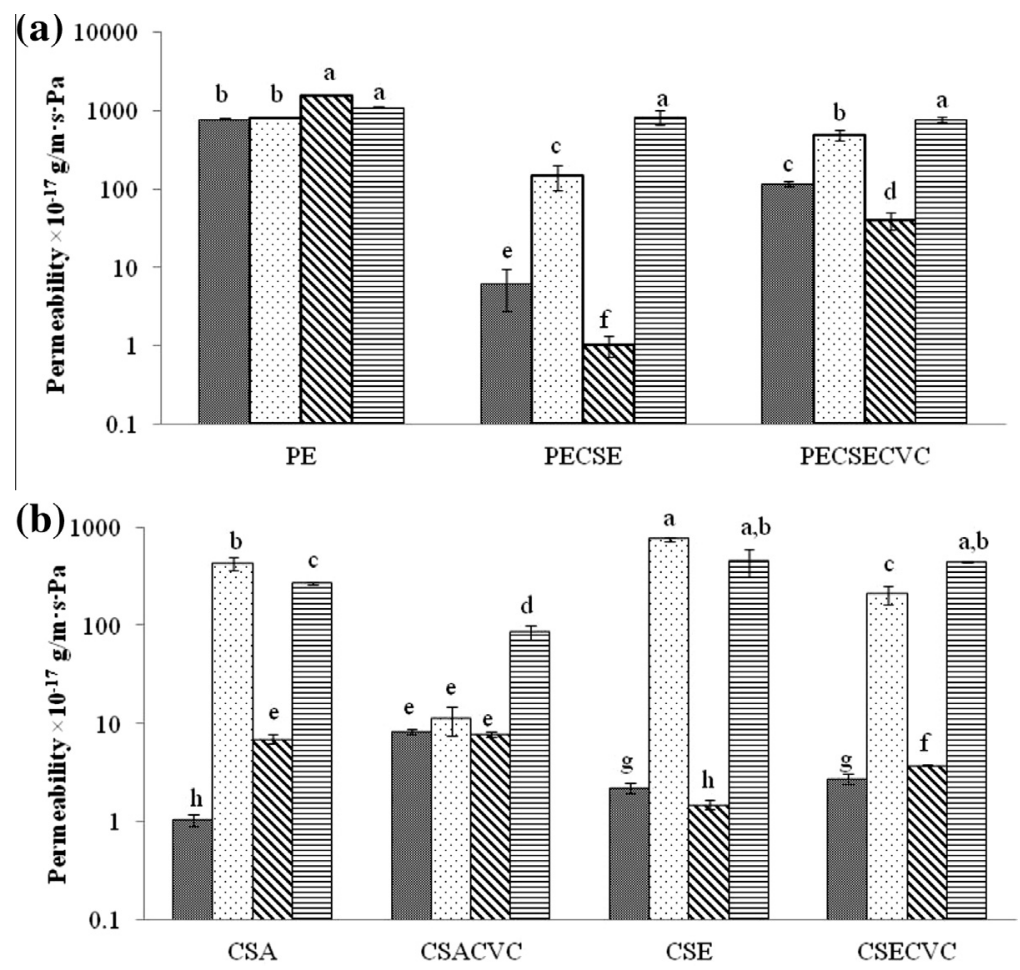

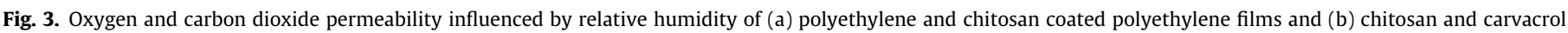

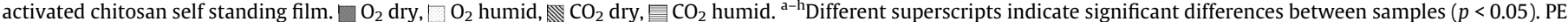

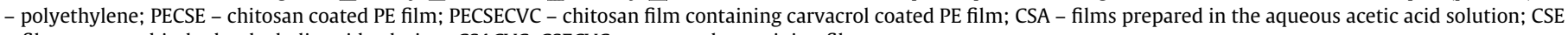
- films prepared in hydroalcoholic acid solution; CSACVC, CSECVC - carvacrol containing films.

network that became more mobile attributed to the presence of carvacrol microdroplets.

As the $\mathrm{RH}$ increased, the $\mathrm{PO}_{2}$ and $\mathrm{PCO}_{2}$ of all samples significantly increased. Despond, Espuche, and Domard (2001) found that $\mathrm{PO}_{2}$ and $\mathrm{PCO}_{2}$ increased by 12.9 and 172.7 times, respectively, when $\mathrm{RH}$ increased from $0 \%$ to $100 \%$. In general, there is a competition between water and gas molecules. The plasticizing and/or swelling effect of moisture followed by self association of water molecules (clusters) might have induced rearrangements in the conformation, changes in crystallinity and mobility of the polymer chains and thus changed the permeation of gases through the chitosan film. CSACVC and CSECVC films were less permeable than CSA and CSE films. There are several explications. First, at higher $\mathrm{RH}, \mathrm{T}_{\mathrm{DS}}$ for CSECVC films was higher comparing to pure chitosan films. Thus in humid environment, in the presence of carvacrol the decrease in $\mathrm{PO}_{2}$ can be associated with the increase of the crystallinity. Indeed, authors reported that in semi-crystalline chitosan, the mass transfer is primarily function of the amorphous phase, because the crystalline phase is usually assumed to be impermeable (Ziani, Oses, Coma, \& Maté, 2008). Second, at higher RH there is a competition between water molecules and carvacrol to be bonded with chitosan chains. Then, as mentioned previously, the plasticization effect of water was stronger in non activated samples and $\mathrm{PO}_{2}$ and $\mathrm{PCO}_{2}$ increased. CSACVC films (aqueous acid solvent) were less permeable than CSECVC (hydroalcoholic acid solvent). This can be attributed to the different molecular orientation of the polymeric chains due to solvent nature (Salame \& Steingiser, 1997).

Generally, when comparing gases, higher solubility of $\mathrm{CO}_{2}$ in the water leads to higher $\mathrm{PCO}_{2}$ in humid conditions. In this study, in carvacrol containing samples, $\mathrm{PCO}_{2}$ was higher than $\mathrm{PO}_{2}$, while in the pure chitosan films no significant differences were observed (Fig. 3b). Similarly, Bae et al. (1998) found that $\mathrm{CO}_{2}$ in wet chitosan membranes were 15-17 times more permeable than in the dry chitosan membrane.

\subsection{Carvacrol release from chitosan films}

In the development of active packaging, the remaining concentration of the active compound during processing and controlledrelease of the same one from packaging materials is of major significance as it will extend the antimicrobial effect of the packaging film. Since the carvacrol release and diffusion from the chitosan matrix begins as soon as carvacrol is added to the film-forming solution, this point has been well reported in our previous study (Kurek et al., 2012a). Diffusion can occur through the non hydrated chitosan matrix but will generally be facilitated as the polymer gradually swells in contact with water vapour. In order to quantify the effect of $\mathrm{RH}$ and temperature on the release of carvacrol from chitosan based films, release kinetics and apparent diffusivities of carvacrol were assessed for three relative humidities and three temperatures. Experimental (amounts of carvacrol) and calculated (diffusion coefficient) data are given in Fig. 4. The experimental release kinetics at controlled $\mathrm{RH}(0 \%, 75 \%$ and $>96 \% \mathrm{RH})$ clearly showed that the release was greatly accelerated by saturating the system with the water vapour and increasing the temperature from 4 to $37^{\circ} \mathrm{C}$. Thus after 60 days, the release was the lowest at $0 \% \mathrm{RH}$ and the highest at $>96 \% \mathrm{RH}$. Moreover at $37{ }^{\circ} \mathrm{C}$ and $\mathrm{RH}$ $>96 \%$ already after 2 days more than $98 \%$ of carvacrol was lost, while at $0 \% \mathrm{RH}$ this was significantly lower (only $2 \%$ ). At $0 \% \mathrm{RH}$ even after 60 days remaining carvacrol content was higher than $85 \%$ (for $4{ }^{\circ} \mathrm{C}$ ), $45 \%$ (for $20^{\circ} \mathrm{C}$ ) and $20 \%$ (for $37^{\circ} \mathrm{C}$ ). As long as the structure of the films was not significantly changed, a high retention of carvacrol was maintained. Effect of RH on carvacrol diffusivity was attributed to the plasticization of the chitosan matrix by water. In the high humidity environment, the release of the entrapped compound into the headspace is closely related to the adsorption of water in the material and hydration of the matrix (Whorton \& Reineccius, 1995). Thermodynamically, different states of matter may be assigned to the chitosan chain in contact 

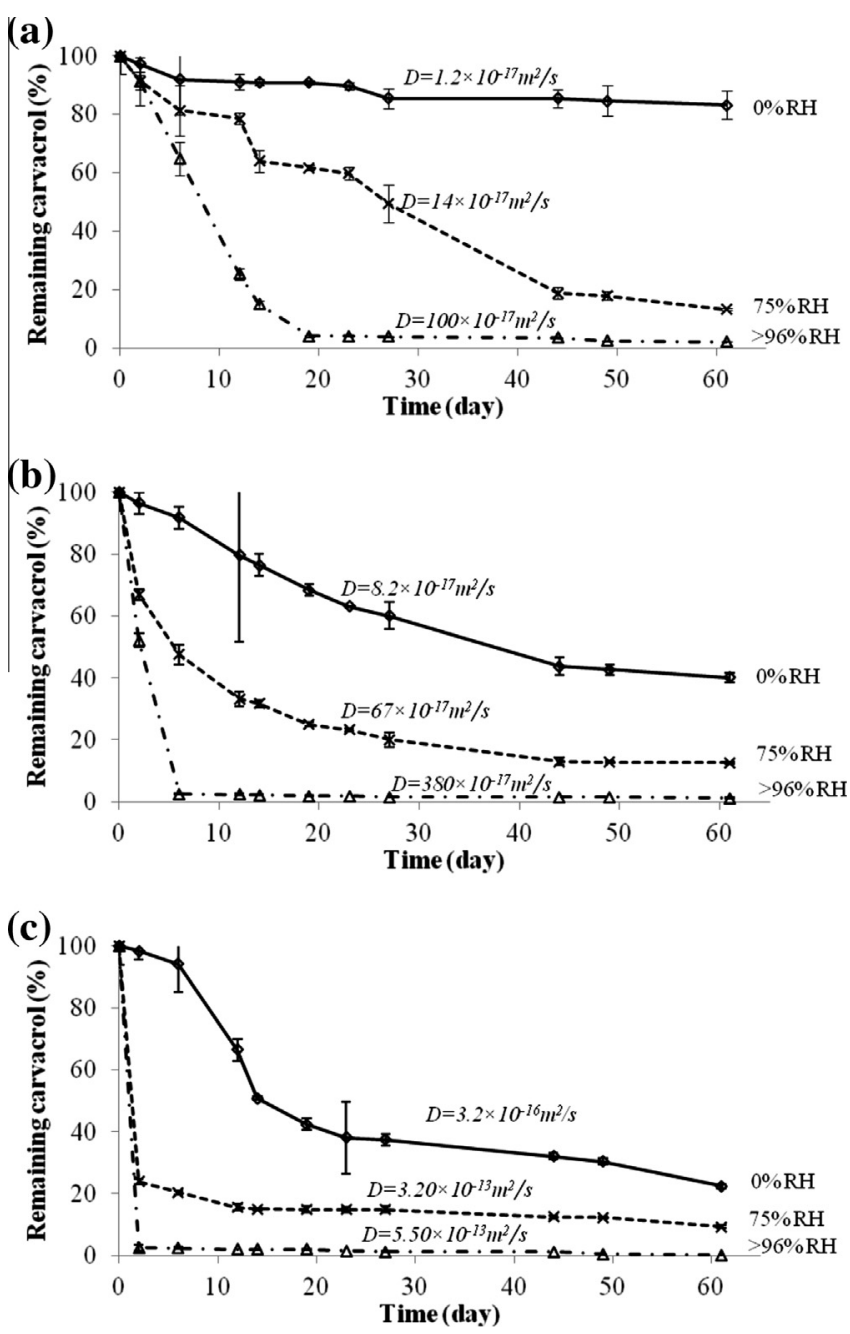

Fig. 4. Kinetic of carvacrol release from chitosan based film during 2 months influenced by relative humidity $\left(0 \%, 75 \%\right.$ and $96 \%$ ) and temperature (a) $4{ }^{\circ} \mathrm{C}$, (b) $20^{\circ} \mathrm{C}$ and (c) $37^{\circ} \mathrm{C}$.

with water vapour molecules. With no doubt, hydrophilic content of the chitosan will affect the intermolecular forces responsible for diffusion and swelling (Ogawa et al., 2004). Water begins to penetrate the surface of the film, followed by cracks appearing near the surface, so subsequent release of carvacrol occurs. During the time, due to its hydrophilicity, chitosan chains are significantly hydrated meaning that the interaction between water and chitosan increases. This facilitates water diffusion, leads to a greater swelling and thus to a greater release of carvacrol. The release mechanisms are quite important from the application point of view. When estimating the shelf life of the active packaging film we want to avoid active compound loss. On the contrary, as soon as the packaging is put in the atmosphere of a 'real fresh food product', where $\mathrm{a}_{\mathrm{w}}$ and thus RH in the packaging is high, accumulated water vapour would favour the release of carvacrol and thus induce the adsorption on the food surface. The antimicrobial effect will thus be obtained.

Depending on the $\mathrm{RH}$ and temperature, the diffusion coefficients (D) of carvacrol varied from $1.2 \times 10^{-17}$ (at $0 \% \mathrm{RH}$ and $4{ }^{\circ} \mathrm{C}$ ) to $55000 \times 10^{-17} \mathrm{~m}^{2} / \mathrm{s}$ (at $100 \% \mathrm{RH}$ and $37^{\circ} \mathrm{C}$ ) (Fig. 4). The slower release in the low $\mathrm{a}_{\mathrm{w}}$ region is most likely due to the lower mobility of carvacrol molecules in the glassy state of the chitosan matrix. The activation energy $\left(E_{a}\right)$ for diffusion may be described as the energy required to create a hole large enough to let by a diffusing molecule. The calculated D was plotted against the reciprocal of absolute temperature (Fig. 5). The diffusion rates

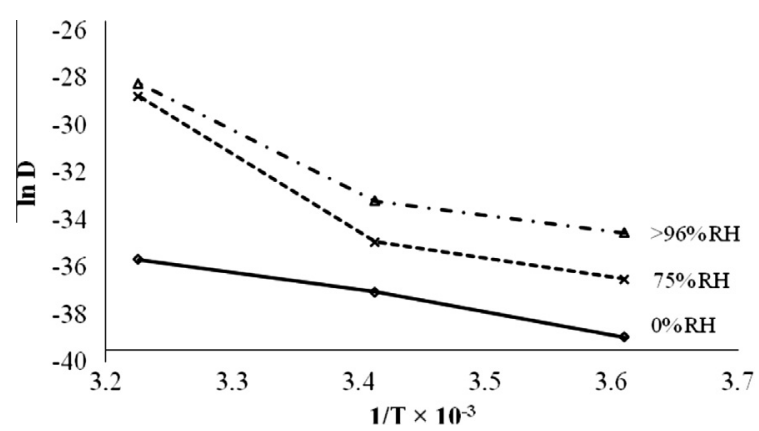

Fig. 5. Influence of temperature and relative humidity on the diffusivity of carvacrol in chitosan film.

significantly increased with the temperature and humidity increase. Tunç and Duman (2011) mentioned that temperature is very effective parameter for controlling the loss of antimicrobial compounds from biopolymer based films. When sufficient amount of $E_{a}$ is available in the system the diffusing molecule jumps from one position to another. For $0 \%, 75 \%$ and $>96 \% \mathrm{RH}$, the activation energies were 71,167 and $136 \mathrm{~kJ} / \mathrm{mol}$ respectively. The diffusivity values were a little bit higher than those obtained for the same compound in soy protein isolate based-matrix (SPI), where at $30{ }^{\circ} \mathrm{C}$ and $\mathrm{RH}$ varying between $60 \%$ and $100 \%$, D ranged from 0.02 to $1.3810^{-14} \mathrm{~m}^{2} / \mathrm{s}$ Chalier, Ben Arfa, Guillard, and Gontard (2009).

\section{Conclusion}

Chitosan films and coatings showed great potential to be used as active aroma compound support matrices. These matrices can provide activity to food packaging films, by humidity and temperature induced release mechanisms. Changes in swelling properties, water vapour permeability and gas permeabilities at high humidity conditions were mostly influenced by structure reorganisation and plasticizing effect of water molecules. At low relative humidity gradients, the incorporation of carvacrol induced a plasticization of chitosan matrix, decreasing its barrier properties. These phenomena were confirmed by the changes in structural properties displayed by thermal analysis. Chitosan coatings significantly improved the gas permeability properties in dry conditions. For PECSE films, $\mathrm{PO}_{2}$ was still the lowest at high RH. Contrarily, lesser improvement was obtained for coatings with carvacrol, especially in the case of carbon dioxide. The release of the active compound was strongly enhanced by $\mathrm{RH}$ as required for the application. During the film storage, the most important was to avoid the active aroma compound loss. That is the reason why the diffusion coefficients had to be low at low RH. Contrarily, regardless of the temperature, as soon as the film is exposed to high humidity (foodstuff), the active compound will be fast released and will provide an immediate antimicrobial efficiency.

\section{Acknowledgements}

The authors wish to thank the colleagues from PAM-PAPC Laboratory. This work was supported by the Ministère de l'Enseignement Supérieur et de la Recherche, the Ministère de l'Economie, de l'Industrie et de l'Emploi, by the way of Fond Unique Interministériel (project EMAC Nº9 290 6395), the Conseil Régional de Bourgogne, Direction Generale de la Competitivite de l'Industrie et des Services DGCIS, Conseil régional Franche-Comté, Conseil Régional Picardie, Conseil Général Côte d'Or, Conseil Général du Jura, le Grand Dijon, the competitive clusters Vitagora, IAR et Plastipolis and all private partners involved in this project. The authors wish to thank Professor JP Gay for English improvement. 


\section{References}

Ashley, R. J. (1985). Permeability and plastics packaging. In J. Comyn (Ed.). Polymer permeability (pp. 269-308). London: Elsevier Applied Science.

Bae, S. Y., Lee, K. H., Yi, S. C., Kim, H. T., Kim, Y. H., \& Kumazawa, H. (1998). CO ${ }_{2}$, N2 gas sorption and permeation behavior of chitosan membrane. Korean Journal of Chemical Engineering, 15, 223-226.

Ben Arfa, A., Combes, S., Preziosi-Belloy, L., Gontard, N., \& Chalier, P. (2006). Antimicrobial activity of carvacrol related to its chemical structure. Letters in Applied Microbiology, 43, 149-154.

Bonilla, J., Atarés, L., Vargas, M., \& Chiralt, A. (2012). Effect of essential oils and homogenization conditions on properties of chitosan-based films. Food Hydrocolloids, 26, 9-16.

Burt, S. (2004). Essential oils: Their antibacterial properties and potential applications in foods - A review. International Journal of Food Microbiology, 94(3), 223-253.

Cagri, A., Ustunol, Z., \& Ryser, E. (2004). Antimicrobial edible films and coatings: A review. Journal of Food Protection, 67(4), 833-848.

Cha, D. S., Cooksey, K., Chinnan, M., \& Park, H. J. (2003). Release of nisin from various heat-pressed and cast films. Lebensmittel-Wissenschaft und-Technologie, 36(2) 209-214.

Chalier, P., Ben Arfa, A., Guillard, V., \& Gontard, N. (2009). Moisture and temperature triggered release of a volatile active agent from soy protein coated paper: Effect of glass transition phenomena on carvacrol diffusion coefficient. Journal of Agricultural and Food Chemistry, 57, 658-665.

Crank, J. (1975). The mathematics of diffusion (2nd ed.). Oxford, London: Claredon Press.

Cunha, A. G., Fernandes, S. C. M., Freire, C. S. R., Silvestre, A. J. D., Neto, C. P., \& Gandini, A. (2008). What is the real value of chitosan's surface energy? Biomacromolecules, 9(2), 610-614.

Debeaufort, F., Martin-Polo, M. O., \& Voilley, A. (1993). Polarity homogenicity and structure affect water vapour permeability of model edible films. Journal of Food Science, 58, 426-434.

Despond, S., Espuche, E. \& Domard, A. (2001). Water sorption and permeation in chitosan films: Relation between gas permeability and relative humidity. Journal of Polymer Science Part B: Polymer Physics, 39, 3114-3127.

Farris, S., Introzzi, L., Biagioni, P., Holz, T., Schiraldi, A., \& Piergiovanni, L. (2011) Wetting of biopolymer coatings: Contact angle kinetics and image analysis investigation. Langmuir, 27, 7563-7574.

Hagenmeier, R., \& Shaw, P. (1991). Permeability of shellac coatings to gases and water vapor. Journal of Agricultural and Food chemistry, 39, 825-829.

Hernández-Muñoz, P., López-Rubio, A., Del-Valle, V., Almenar, E., \& Gavara, R. (2004). Mechanical and water barrier properties of glutenin films influenced by storage time. Journal of Agricultural and Food Chemistry, 52, 79-83.

Karbowiak, T., Debeaufort, F., \& Voilley, A. (2006). Importance of surface tension characterization for food, pharmaceutical and packaging products: A Review. Critical Reviews in Food Science and Nutrition, 46, 1-17.

Kokoszka, S., Debeaufort, F., Hambleton, A., Lenart, A., \& Voilley, A. (2010). Protein and glycerol contents affects physico-chemical properties of soy protein isolatebased edible films. Innovative Food Science and Emerging Technologies, 11, 503-510.
Kurek, M., Descours, E., Galić, K., Voilley, A., \& Debeaufort, F. (2012a). How composition and process parameters affect volatile active compounds in biopolymer films. Carbohydrate Polymers, 88, 646-656.

Kurek, M., Brachais, C.-H., Ščetar, M., Voilley, A., Galić, K., Couvercelle, J.P., \& Debeaufort, F. (2012b). Carvacrol affects interfacial, structural and transfer properties of chitosan coated polyethylene. Carbohydrate Polymers, in press.

Kurek, M., Brachais, C.-H., Nguimjeu, C. M., Bonnotte, A., Voilley, A., Galić, K., \& Debeaufort, F. (2012c). Structure and thermal properties of a chitosan coated polyethylene bilayer film. Polymer Degradation and Stability, 1-9.

Kurek, M., Ščetar, M., Voilley, A., Galić, K., \& Debeaufort, F. (2012d). Barrier properties of chitosan coated polyethylene. Journal of Membrane Science, 404$405,162-168$.

Li, B., Kennedy, J. F., Peng, J. L., Yie, X., \& Xie, B. J. (2006). Preparation and performance evaluation of glucomannan-chitosan-nisin ternary antimicrobial blend film. Carbohydrate Polymers, 65(4), 488-494.

McHugh, T. H., Aujard, J.-F., \& Krochta, J. M. (1994). Plasticized whey protein edible films: Water vapor permeability properties. Journal of Food Science, 59, 416-419.

Nostro, A., \& Papalia, T. (2012). Antimicrobial activity of carvacrol: Current progress and future prospective. Recent Patents on Anti-Infective Drug Discovery, 7(1), 28-35.

Ogawa, K., Yui, T., \& Okuyama, K. (2004). Three D structures of chitosan. International Journal of Biological Macromolecules, 34, 1-8.

Peroval, C., Debeaufort, F., Despre, D., \& Voilley, A. (2002). Arabinoxylan-lipid-based edible films: Water vapour permeance and others physical properties. Journal of Agricultural and Food Chemistry, 50(14), 3977-3983.

Phan, T. D., Debeaufort, F., Luu, D., \& Voilley, A. (2005). Functional properties of edible agar-based and starch-based films for food quality preservation. Journal of Agricultural and Food Chemistry, 53, 973-981.

Salame, M., \& Steingiser, S. (1997). Barrier polymers. Polymer - Plastics Technology and Engineering, 8, 155-175.

Sollogoub, C., Guinault, A., Bonnebat, C., Bennjima, M., Akrour, L., Fauvarque, J. F., et al. (2009). Formation and characterization of crosslinked membranes for alkaline fuel cells. Journal of Membrane Science, 335, 37-42.

Tunç, S., \& Duman, O. (2011). Preparation of active antimicrobial methyl cellulose/ carvacrol/montmorillonite nanocomposite films and investigation of carvacrol release. LWT - Food Science and Technology, 44, 465-472.

Vogler, E. A. (1998). Structure and reactivity of water at biomaterial surfaces. Advances in Colloid and Interface Science, 74(1-3), 69-117.

Whorton, C., \& Reineccius, G. (1995). Evaluation of the mechanisms associated with the release of encapsulated flavor materials from maltodextrin matrices. In S. J. Risch \& G. A. Reineccius (Eds.), Encapsulation and controlled release of food ingredients (pp. 143-160). Washington: ACS Symposium Series, American Chemical Society.

Yakimets, I., Paes, S. S., Wellner, N., Smith, A. C., Wilson, R. H., \& Mitchell, J. R. (2007). Effect of water content on the structural reorganization and elastic properties of biopolymer films: A comparative study. Biomacromolecules, 8, 1710-1722.

Ziani, K., Oses, J., Coma, V., \& Maté, J. I. (2008). Effect of the presence of glycerol and Tween 20 on the chemical and physical properties of films based on chitosan with different degree of deacetylation. LWT - Food Science and Technology, 41, 2159-2165. 